\title{
Achieving social equity by addressing the needs of disabled people in heritage building conservation in Malaysia.
}

\begin{abstract}
Social equity is one of the three main thrusts for a country's sustainable development that is achieved only when a country fulfills the needs of everyone including those of disabled people. It is known that the design, implementation and management of heritage buildings, undertaken by both the public and private sectors, are influenced by conservation practices that may not consider the needs of disabled people. In Malaysia, with the passing of the National Heritage Act in 2005, it is important to ensure that conservation practices follow sustainable development principles, in particular, social equity. Our paper aims to show the extent to which services for disabled people are being provided in the Malaysian heritage tourism sector through four case studies of heritage buildings. The case studies were conducted to ascertain whether the concepts of Barrier-Free, which are 1. Accessibility, 2. Usability and 3. Safety, were adhered to in the design and management aspects of building conservation. Our survey method was using access audits based on the country's standards and international guidelines. The results show that in all cases some attempts were made to create accessibility, but often conservation objectives tend to over-ride access. Clearly, a lot is still to be done to ensure that accessibility for disabled people is addressed in Malaysia.
\end{abstract}

Keyword: Social equity; Disabled people; Access audits; Heritage building. 